\title{
Predictors of inhospital mortality and re-hospitalization in older adults with community-acquired pneumonia: a prospective cohort study
}

\author{
Binod Neupane1, Stephen D Walter ${ }^{1}$, Paul Krueger2, Tom Marrie ${ }^{3}$ and Mark Loeb*1,4,5
}

\begin{abstract}
Background: A better understanding of potentially modifiable predictors of in-hospital mortality and re-admission to the hospital following discharge may help to improve management of community-acquired pneumonia in older adults. We aimed to assess the associations of potentially modifiable factors with mortality and re-hospitalization in older adults hospitalized with community-acquired pneumonia.

Methods: A prospective cohort study was conducted from July 2003 to April 2005 in two Canadian cities. Patients aged 65 years or older hospitalized for community-acquired pneumonia were followed up for up to 30 days from initial hospitalization for mortality and these patients who were discharged alive within 30 days of initial hospitalization were followed up to 90 days of initial hospitalization for re-hospitalization. Separate logistic regression analyses were performed identify the predictors of mortality and re-hospitalization.

Results: Of 717 enrolled patients hospitalized for community-acquired pneumonia, 49 (6.8\%) died within 30 days of hospital admission. Among these patients, 526 were discharged alive within 30 days of hospitalization of whom 58 (11.2\%) were re-hospitalized within 90 days of initial hospitalization. History of hip fracture (odds ratio $(O R)=4.00,95 \%$ confidence interval $(\mathrm{Cl})=(1.46,10.96), \mathrm{P}=.007)$, chronic obstructive pulmonary disease $(\mathrm{OR}=2.31,95 \% \mathrm{Cl}=(1.18,4.50)$, $\mathrm{P}=.014)$, cerebrovascular disease $(\mathrm{OR}=2.11,95 \% \mathrm{Cl}=(1.03,4.31), \mathrm{P}=.040)$ were associated with mortality. Male sex $(\mathrm{OR}=2.35,95 \% \mathrm{Cl}=(1.13,4.85), \mathrm{P}=.022)$ was associated with re-hospitalization while vitamin $\mathrm{E}$ supplementation was protective $(\mathrm{OR}=0.37(0.16,0.90), \mathrm{P}=.028)$. Lower socioeconomic status, prior influenza and pneumococcal vaccinations, appropriate antibiotic prescription upon admission, and lower nutrition risk were not significantly associated with mortality or re-hospitalization.
\end{abstract}

Conclusion: Chronic comorbidities appear to be the most important predictors of death and re-hospitalization in older adults hospitalized with community-acquired pneumonia while vitamin E supplementation was protective.

\section{Background}

Community-acquired pneumonia (CAP) is one of the leading causes of mortality in older adults aged 65 years or more [1-6]. Re-hospitalization due to pneumonia after premature hospital discharge or due to new or worsening

* Correspondence: loebm@mcmaster.ca

1 Department of Clinical Epidemiology and Biostatistics, McMaster University, Hamilton, Ontario, Canada

Full list of author information is available at the end of the article of co-existing medical complications is associated with extra use of medical resources, increased costs and deaths [7].

Demographic factors such as age and comorbidities such as chronic lung diseases (COPD) may not fully explain mortality and re-hospitalization associated with CAP in the elderly. A better understanding of potentially modifiable predictors of in-hospital mortality and readmission to the hospital following discharge may help to 
improve management of pneumonia in this vulnerable population. However, conflicting evidence exists regarding the role of modifiable factors, such as influenza and pneumococcal vaccines [8-10] and guideline-based antimicrobial use [11-14]. Malnutrition has been found to be associated with mortality $[15,16]$ and re-admission [15] of patients discharged alive within 30 days of initial hospitalization. Poor functional status has also been associated with 30-day in-hospital mortality $[15,17]$. However, this finding was not seen in another study [18]. Problems with these studies include small sample sizes [14-18], retrospective designs based on administrative records $[11,12]$, and/or failure to use rigorous definition of CAP [18]. Accurate identification of pneumonia cases could be a problem especially in retrospective studies using administrative data (where up to $40 \%$ of all cases of pneumonia diagnosed by ER physicians were not confirmed as so by radiologists) [19].

In this prospective cohort study where all pneumonia cases were confirmed by radiologists, we sought to identify the predictors of 30-day mortality in older adults with CAP and hospital re-admission within 90 days among these patients who were discharged alive to home, nursing home or another hospital within 30 days of their initial hospitalization. We specifically sought to assess the associations of potentially modifiable risk factors including immunization history, empiric antimicrobial use, as well as socioeconomic, nutritional and functional statuses.

\section{Methods}

\section{Study Participants}

In this prospective cohort study, patients aged 65 years and older who were hospitalized for CAP in 10 hospitals in Hamilton, Ontario and Edmonton, Alberta, Canada were enrolled from 2003 to 2005. There are four emergency departments (EDs) in Hamilton, serving a catchment area of approximately 2.2 million people, and six EDs in Edmonton, serving a catchment area of about 1 million people. Eligible participants had to live in one of these two catchment area communities and have at least two of the following signs and symptoms: temperature $>38^{\circ} \mathrm{C}$, productive cough, chest pain, shortness of breath, or crackles on auscultation. They also had to have a new opacity on a chest radiograph that was interpreted by a radiologist as being compatible with pneumonia. Exclusion criteria were residing in a nursing home and infection at another site in addition to CAP.

The study was approved by the Hamilton Health Sciences Research Ethics Board, St. Joseph's Hospital Research Ethics Board, and the University of Alberta Research Ethics Board. Informed consent was obtained from all participants.

\section{Data}

Trained interviewers collected health data of the initial hospital admission after the patients were identified in EDs and enrolled in the study. Demographic, comorbidity, lifestyle and other health related data were collected from patients by personal interviews using structured questionnaires and additional complementary information was extracted from patients' medical charts. The demographic variables included age, sex, height and weight to calculate body mass index, marital status (whether married and living with spouse or not), and living arrangement (alone or in a family). Comorbidity variables included asthma, cancer, chronic obstructive pulmonary disease (COPD), congestive heart failure, cerebrovascular disease, liver disease, renal disease, and diabetes mellitus. In addition, data was collected on mental confusion, vital signs, empiric antibiotics used upon admission, medication history including use of vitamins, minerals and immunosuppression drugs, and influenza and pneumococcal immunizations prior to hospital admission.

Level of education was used as a proxy for socioeconomic status since older adults may not have income from active employment. Patients were considered having low socioeconomic status if they had less than high school education. Life-style variables included smoking (whether or not a patient smoked 100 or more cigarettes in lifetime), household smoking (whether or not any member in the patient's family smoked), amount of alcohol consumption (mean grams of alcohol per month in the last 12 months). Nutritional status was assessed using a 15-item adaptation of the Nutrition Screening Initiative Level I 10 statement [20] and the Mini-Nutritional Assessment [21,22], with scores ranging from 0 (high nutritional risk) to 60 (no nutritional risk). Patient's functional status was assessed using 10-item modified Barthel Index [23], with scores ranging from 0 (full dependence) to 20 (complete independence). The data were highly skewed with most participants having high scores; we dichotomized the Barthel Index score into 17 or less for lower functional status (some dependency) versus 18 to 20 for higher functional status (slight to no dependency). Severity of pneumonia illness at presentation was assessed using the British Thoracic Society's severity of illness index CRB-65 [24]. The CRB-65 score ranges from 1 (not severe) to 4 (highly severe) for elderly population. This is a more practical index for assessing severity of pneumonia illness at presentation because it is easy and quick to assess the severity, where blood urea measurement is omitted from the CURB-65 scale [24]. Antibiotics prescribed on admission were defined as "appropriate" if they were respiratory fluroqualone alone or a combination of advance macrolide and beta-lactum antibiotics. 
This classification is based on Canadian guidelines for the management of CAP in an in-patient setting [25].

Patients were followed up for 30 days from initial hospitalization for their mortality. The patients discharged alive to home, nursing home or another hospital within 30 days of initial hospitalization were followed up to 90 days of initial hospitalization and their hospital re-admission was determined by telephone interview or review of medical charts.

\section{Statistical Analysis}

For the statistical analysis, we defined the outcome "mortality" event as any death that occurred within 30 days of the initial hospital admission. We also did a sensitivity analysis where we alternatively defined "mortality" outcome as any deaths within 30 days compared to discharges alive within 30 days, while excluding patients who were still in the hospital more than 30 days after the initial admission. "Re-hospitalization" was defined as hospitalization for any reason within 90 days of the initial hospitalization among those patients who were discharged alive within 30 days of the initial hospitalization.

In the univariate analysis, we tested the crude associations of variables of interest using two-sided tests (Chisquared tests for binary variables and t-tests for continuous variables) with the mortality and readmission outcomes. Association was expressed as odds ratio (OR) with corresponding 95\% confidence interval (CI) for each binary variable and as mean difference with corresponding 95\% CI for each continuous variable.

In the multivariable regression model, certain variables of interest (i.e. lower socioeconomic status, appropriate antibiotic prescription upon admission, influenza vaccination, pneumococcal vaccination, lower nutritional risk (i.e., higher nutrition score), and lower functional status) were selected a priori for adjustment whereas the other variables were considered as candidate variables for multivariable model of each outcome if they had p-value of $\leq$ .10 in the corresponding univariate analysis. We used logistic regression with a step-wise backward elimination approach to develop the final model for mortality and rehospitalization separately. Thus, the final model for each outcome included the variables selected $a$ priori and any other variables that remained statistically significant $(\mathrm{p}<$ 0.05) in two-sided tests. Adjusted associations are expressed as ORs and corresponding 95\% CIs.

Data were analyzed using SAS for Windows version 9.1 (SAS Institute Inc. Cary, NC).

\section{Results}

There were 717 patients (365 from Hamilton and 352 from Edmonton) enrolled. Forty nine (6.8\%) died within 30 days and $603(84.1 \%)$ were alive at 30 days of hospital admission of whom 526 (73.3\%) were discharged alive from the hospitals to their homes, nursing homes or another hospitals and $77(10.7 \%)$ were still in the same hospitals for more than 30 days (see Figure 1). Fifty eight (11.0\%) of 526 patients discharged alive within 30 days of initial hospitalization were re-admitted within 90 days of initial hospitalization. Descriptive statistics by outcome status and unadjusted associations of factors with mortality and re-hospitalization are presented in Table 1 and Table 2, respectively. Adjusted associations with mortality and re-hospitalization are presented in Table 3 and 4, respectively.

In the multivariable model, history of hip fracture (OR $=4.00,95 \% \mathrm{CI}=(1.46,10.96), \mathrm{P}=.007)$, chronic obstructive pulmonary disease $(\mathrm{OR}=2.31,95 \% \mathrm{CI}=(1.18,4.50)$, $\mathrm{P}=.014)$, and cerebrovascular disease $(\mathrm{OR}=2.11,95 \% \mathrm{CI}$ $=(1.03,4.31), \mathrm{P}=.040)$ were significantly associated with mortality (Table 3). In the sensitivity analysis that excluded patients who remained in hospital for more than 30 days, essentially the same results were found.

Only male sex $(\mathrm{OR}=2.35,95 \% \mathrm{CI}=(1.13,4.85), \mathrm{P}=$ .022) was significantly associated with re-hospitalization while vitamin $\mathrm{E}$ supplementation was protective $(\mathrm{OR}=$ 0.37 (0.16, 0.90), $\mathrm{P}=.028)$ (Table 4).

\section{Discussion}

We found that in older adults hospitalized with pneumonia, there was an increased risk of inhospital mortality associated with hip fracture, chronic obstructive pulmonary disease, and cerebrovascular disease. These findings are consistent with previous reports [14,26-28]. Among patients discharged from hospital within first 30 days, being male was associated with hospital re-admission within 90 days of initial hospitalization.

Taking vitamin E supplements was protective of re-hospitalization in our study. Vitamin E inadequacy leads to increased prostaglandin (PG)E2 production by alveolar macrophages, a hypothesized mechanism through which vitamin E deficiency may suppress T-cell-mediated immunity [29]. However, the clinical effect on outcomes is not well defined, with some studies showing benefit in those with deficiencies and other studies showing no benefit [30]. The fact however that these results are based on self-reported use of Vitamin $\mathrm{E}$ is an important limitation.

Lower educational level was not significantly associated with re-hospitalization. This is in contrast to other reports where lower education status and lack of employment have been associated with re-hospitalization in poor urban areas [30,31]. Given the risk of re-hospitalization nearly twice as high in those with lower educational status where p-value was close to .05 and many variables were adjusted for sample size that was reduced for rehospitalization due missing values, it is possible that our 
Table 1: Descriptive statistics by mortality status and crude associations with mortality within $\mathbf{3 0}$ days of initial hospitalization for community acquired pneumonia.

\begin{tabular}{|c|c|c|c|c|}
\hline \multirow[t]{2}{*}{ Factors $^{a}$} & \multirow{2}{*}{$\begin{array}{c}\text { Mortality within } 30 \\
\text { days }(n=49)\end{array}$} & \multirow{2}{*}{$\begin{array}{l}\text { Alive at } 30 \text { days } \\
\quad(n=603)\end{array}$} & \multicolumn{2}{|c|}{ Mortality vs. alive at 30 days } \\
\hline & & & OR $(95 \% \mathrm{CI})$ & $\mathbf{P}$ \\
\hline \multicolumn{5}{|l|}{ Demographic factors } \\
\hline Age (years) ${ }^{b}$ & $79.3(8.6)$ & $79.1(7.6)$ & $0.26(-1.98,2.50)$ & .819 \\
\hline Male Sex & $31(64.6)$ & $365(60.4)$ & $1.19(0.65,2.21)$ & .571 \\
\hline $\begin{array}{l}\text { Married, living with } \\
\text { spouse }\end{array}$ & $29(60.4)$ & $310(51.8)$ & $1.42(0.78,2.58)$ & .252 \\
\hline Living Alone & $13(26.5)$ & $187(32.6)$ & $0.75(0.39,1.44)$ & .384 \\
\hline $\mathrm{BMI}^{\mathrm{a}}$ & $24.7(4.7)$ & $25.4(5.9)$ & $-0.67(-2.49,1.15)$ & .471 \\
\hline \multicolumn{5}{|l|}{$\begin{array}{l}\text { Low socioeconomic } \\
\text { status }\end{array}$} \\
\hline $\begin{array}{l}\text { Education (< high } \\
\text { school) }\end{array}$ & $32(65.3)$ & $366(61.5)$ & $1.18(0.64,2.17)$ & .599 \\
\hline \multicolumn{5}{|l|}{$\begin{array}{l}\text { Empiric Antibiotic } \\
\text { Use }\end{array}$} \\
\hline $\begin{array}{l}\text { Appropriate } \\
\text { Antibiotics }\end{array}$ & $44(89.8)$ & $511(83.9)$ & $1.69(0.65,4.36)$ & .275 \\
\hline \multicolumn{5}{|l|}{ Pneumonia Severity } \\
\hline CRB-65a & $1.52(0.7)$ & $1.54(0.7)$ & $-0.02(-0.21,0.17)$ & .834 \\
\hline \multicolumn{5}{|l|}{ Immunization history } \\
\hline Influenza Vaccine & $38(77.6)$ & $473(79.0)$ & $0.92(0.46,1.85)$ & .816 \\
\hline Pneumococcal Vaccine & $24(49.0)$ & $342(57.8)$ & $0.70(0.39,1.26)$ & .232 \\
\hline \multicolumn{5}{|l|}{ Comorbidities } \\
\hline Asthma & $13(27.7)$ & $142(24.0)$ & $1.21(0.62,2.35)$ & .576 \\
\hline Cancer & $11(22.9)$ & $156(26.3)$ & $0.83(0.41,1.67)$ & .607 \\
\hline $\begin{array}{l}\text { Cerebrovascular } \\
\text { Disease }^{c}\end{array}$ & $16(33.3)$ & $115(19.3)$ & $2.08(1.11,3.93)$ & .021 \\
\hline $\begin{array}{l}\text { Congestive Heart } \\
\text { Failure }\end{array}$ & $18(39.1)$ & $196(33.5)$ & $1.28(0.69,2.36)$ & .438 \\
\hline $\mathrm{COPD}^{c}$ & $31(66.0)$ & $284(48.0)$ & $2.10(1.13,3.92)$ & .018 \\
\hline Diabetes Mellitus & $8(16.7)$ & $155(26.0)$ & $0.57(0.26,1.24)$ & .152 \\
\hline Dysphagia & $10(20.8)$ & $78(13.2)$ & $1.73(0.83,3.62)$ & .138 \\
\hline Hip Fracturec & $7(14.6)$ & $29(4.9)$ & $3.33(1.38,8.07)$ & .005 \\
\hline Liver Diseasec, d & $4(8.7)$ & $11(1.9)$ & $5.03(1.54,16.48)$ & .003 \\
\hline Renal Disease & $9(20.0)$ & $109(18.6)$ & $1.10(0.51,2.34)$ & .812 \\
\hline \multicolumn{5}{|l|}{$\begin{array}{l}\text { Mineral supplement } \\
\text { and medication } \\
\text { history }\end{array}$} \\
\hline $\begin{array}{l}\text { Vitamin } \mathrm{E} \\
\text { Supplementation }\end{array}$ & $9(18.3)$ & $134(23.1)$ & $0.75(0.35,1.58)$ & .448 \\
\hline Zinc Supplementation & $5(10.2)$ & $65(11.4)$ & $0.88(0.34,2.30)$ & .796 \\
\hline $\begin{array}{l}\text { Immunosuppressive } \\
\text { Drugs }\end{array}$ & $8(18.2)$ & $93(16.4)$ & $1.13(0.51,2.51)$ & .760 \\
\hline
\end{tabular}


Table 1: Descriptive statistics by mortality status and crude associations with mortality within 30 days of initial hospitalization for community acquired pneumonia. (Continued)

\begin{tabular}{|c|c|c|c|c|}
\hline \multicolumn{5}{|l|}{ Lifestyle factors } \\
\hline $\begin{array}{l}\text { Smoking (> } 100 \\
\text { cigarettes) }\end{array}$ & 39 (79.6) & $447(74.3)$ & $1.35(0.66,2.77)$ & .409 \\
\hline Household Smoking & $11(22.5)$ & $111(18.4)$ & $1.28(0.63,2.58)$ & .489 \\
\hline $\begin{array}{l}\text { Alcohol (gram/ } \\
\text { month) }\end{array}$ & $16.1(41.3)$ & $10.6(36.8)$ & $5.46(-5.48,16.40)$ & .328 \\
\hline Nutritional Score & $45.3(8.8)$ & $47.0(6.8)$ & $-1.70(-3.76,0.35)$ & .198 \\
\hline \multicolumn{5}{|c|}{ Low functional status } \\
\hline Barthel Score $(\leq 17)$ & $12(24.5)$ & $142(23.7)$ & $1.04(0.53,2.06)$ & .901 \\
\hline
\end{tabular}

study did not have sufficient power to demonstrate such an association.

Neither influenza nor pneumococcal vaccine appeared to have any protective effect on mortality or re-hospitalization. In a study, Herzog et al. found influenza vaccination to be protective against mortality and readmission in older adults hospitalized with pneumonia [8]. However, there are conflicting reports for pneumococcal vaccination $[9,10]$. It should be noted, however, that one of the concerns using observational designs to determine the benefits associated with immunizations is that individuals who are healthier may be more likely to be immunized and this could be the reason for observed protective effects. Moreover, thelow rate of death at 30 days (6.8\%) may have limited our ability to detect a significant protective effect of pneumococcal vaccine.

We found no significant association between nutritional status and mortality or re-hospitalization. In contrast, Vecchiarino et al. found a positive association of death and re-hospitalization with malnutrition, assessed on the basis of a low serum albumin or a reported unintentional weight loss [15]. Requelme et al. also found a significant association between nutrition and mortality [16]. There are several possible explanations for these differences. For example, we might not have sufficient mortality and re-hospitalization cases to detect such associations in this cohort study. In addition, our sample was fairly homogeneous in terms of nutrition risk with $84.2 \%$ having higher one-third nutrition scores (scores between 40 and 60). As a result, our measurement might not have adequately discriminated high risk and low risk patients in terms of mortality or re-hospitalization.

We also did not observe any association between functional status and mortality or re-hospitalization. Vecchiarino et al. [15] and Cabre et al. [17], on the other hand, found that poor functional status was associated with 30day mortality. However, the association with mortality was not significant in Mody and Bradley study [18]. One possible explanation is that the Barthel Index was insufficiently discriminatory in our population where most of the patients had very high Barthel scores.

Previous data suggest that appropriate antibiotic prescription prior to hospital admission is associated with reduced mortality in patients with community-acquired pneumonia [12,13]. However, we did not find such an association. This may be because there were relatively few inappropriate prescriptions (only $15.6 \%$ of all antibiotic prescriptions); so those who died were mostly from initial antibiotic appropriately prescribed group. Also, we might not expect an association between appropriate antibiotic prescription and re-hospitalization because impact of appropriate antibiotic prescription would have attenuated prior to hospital discharge when patients' conditions have stabilized (absence of fever and severe respiratory distress). Therefore, complications during hospitalization or new or coexisting medical illnesses would have potentially greater impact on re-hospitalization. Alternatively, there might be also significant variation in the effectiveness of different types and generations of antibiotics that we termed 'appropriate' collectively, especially among more severely ill patients who are more likely to die or have more severe complications[31].

We found associations between traditional variables and outcomes. But, none of the variables that we tested as potentially modifiable variables appeared to be statistically significant. Strength of our multi-centered study is that we considered pure pneumonia cases confirmed by radiologists following strict selection criteria where all exposure information was obtained prospectively. We also adjusted many variables of interests or confounding 
Table 2: Descriptive statistics by re-hospitalization status and crude associations with re-hospitalization with 90 days of initial hospitalization for community acquired pneumonia.

Factors $^{\mathbf{a}}$ Re-hospitalization within 90 days of initial hospitalization

\begin{tabular}{|c|c|c|c|}
\hline $\begin{array}{c}\text { Yes } \\
(n=58)\end{array}$ & $\begin{array}{c}\text { No } \\
(n=261)\end{array}$ & OR (95\% CI) & $\mathbf{P}$ \\
\hline
\end{tabular}

\begin{tabular}{|c|c|c|c|c|}
\hline \multicolumn{5}{|l|}{ Demographic factors } \\
\hline Age (years) ${ }^{b}$ & $79.3(7.1)$ & $79.8(7.8)$ & $-0.47(-2.67,1.72)$ & .673 \\
\hline Male Sex ${ }^{c}$ & $44(75.9)$ & $150(58.1)$ & $2.26(1.18,4.34)$ & .012 \\
\hline $\begin{array}{l}\text { Married, living with } \\
\text { spouse }\end{array}$ & $33(58.9)$ & $131(50.4)$ & $1.41(0.79,2.54)$ & .246 \\
\hline Living Alone & $13(23.2)$ & $84(34.2)$ & $0.58(0.30,1.14)$ & .114 \\
\hline BMla & $25.5(6.0)$ & $25.3(5.6)$ & $0.21(-1.49,1.91)$ & .810 \\
\hline \multicolumn{5}{|l|}{$\begin{array}{l}\text { Low socioeconomic } \\
\text { status }\end{array}$} \\
\hline $\begin{array}{l}\text { Education }(<\text { high } \\
\text { school)c }\end{array}$ & $45(79.0)$ & $158(62.0)$ & $2.30(1.16,4.57)$ & .015 \\
\hline \multicolumn{5}{|l|}{$\begin{array}{l}\text { Empiric Antibiotics } \\
\text { Use }\end{array}$} \\
\hline $\begin{array}{l}\text { Appropriate } \\
\text { Antibiotics }\end{array}$ & $50(86.2)$ & $216(82.8)$ & $1.30(0.58,2.93)$ & .523 \\
\hline \multicolumn{5}{|l|}{ Pneumonia Severity } \\
\hline CRB-65a & $1.5(0.6)$ & $1.56(0.7)$ & $-0.06(-0.25,0.13)$ & .555 \\
\hline \multicolumn{5}{|l|}{ Immunization history } \\
\hline Influenza Vaccination & $48(82.8)$ & $198(78.0)$ & $1.36(0.65,2.85)$ & .419 \\
\hline $\begin{array}{l}\text { Pneumococcal } \\
\text { Vaccination }\end{array}$ & $33(58.9)$ & $142(55.3)$ & $1.16(0.64,2.09)$ & .616 \\
\hline \multicolumn{5}{|l|}{ Comorbidities } \\
\hline Asthma & $14(25.5)$ & $62(24.5)$ & $1.05(0.54,2.06)$ & .882 \\
\hline Cancer & $17(32.1)$ & $66(26.0)$ & $1.35(0.71,2.55)$ & 364 \\
\hline $\begin{array}{l}\text { Congestive Heart } \\
\text { Failure }\end{array}$ & $24(43.6)$ & $95(37.9)$ & $1.27(0.70,2.30)$ & 425 \\
\hline COPD & $32(58.2)$ & $131(51.2)$ & $1.33(0.74,2.39)$ & 345 \\
\hline Diabetes Mellitus & $14(25.0)$ & $66(25.5)$ & $0.97(0.50,1.90)$ & 940 \\
\hline Dysphagia & $10(17.9)$ & $38(14.9)$ & $1.24(0.58,2.67)$ & 579 \\
\hline Hip Fracture & $2(3.58)$ & $11(4.28)$ & $0.83(0.18,3.84)$ & 810 \\
\hline Liver Disease & $1(1.8)$ & $2(0.8)$ & $2.3(0.20,25.82)$ & 488 \\
\hline Renal Disease & $13(23.2)$ & $40(15.8)$ & $1.61(0.79,3.26)$ & 184 \\
\hline \multicolumn{5}{|l|}{$\begin{array}{l}\text { Mineral supplement } \\
\text { and medication } \\
\text { history }\end{array}$} \\
\hline $\begin{array}{l}\text { Vitamin E } \\
\text { Supplementationc }\end{array}$ & $8(15.1)$ & $73(28.9)$ & $0.44(0.20,0.97)$ & 039 \\
\hline Zinc Supplementation & $5(9.6)$ & $33(13.4)$ & $0.69(0.26,1.86)$ & 461 \\
\hline Immunosuppressive & $14(25.0)$ & $40(16.1)$ & $1.73(0.87,3.47)$ & 117 \\
\hline
\end{tabular}


Table 2: Descriptive statistics by re-hospitalization status and crude associations with re-hospitalization with 90 days of initial hospitalization for community acquired pneumonia. (Continued)

\begin{tabular}{|c|c|c|c|c|}
\hline \multicolumn{5}{|l|}{ Lifestyle factors } \\
\hline $\begin{array}{l}\text { Smoking (> } 100 \\
\text { cigarettes) }\end{array}$ & $44(77.2)$ & $201(77.3)$ & $0.99(0.50,1.97)$ & 985 \\
\hline Household Smoking & $12(21.1)$ & $47(18.1)$ & $1.21(0.59,2.46)$ & 601 \\
\hline $\begin{array}{l}\text { Alcohol (gram/ } \\
\text { month)a, }\end{array}$ & $5.8(15.8)$ & $10.6(31.6)$ & $-4.86(-13.33,3.61)$ & 093 \\
\hline Nutritional Score ${ }^{a}$ & $48.7(5.9)$ & $47.3(6.7)$ & $1.41(-0.49,3.31)$ & 145 \\
\hline \multicolumn{5}{|l|}{ Low functional status } \\
\hline Barthel Score $(\leq 17)$ & $9(15.8)$ & $60(23.2)$ & $0.62(0.29,1.34)$ & 222 \\
\hline
\end{tabular}

variables in order to minimize bias in the results. However, this was also the limitation of the study in terms of statistical power of the study because we had only few mortality and re-hospitalization events and the variables we assessed as potentially modifiable factors for mortality or re-hospitalization were either very common or very rare exposures in our cohort. Also, the effective sample size used for re-hospitalization was very small and as a consequence factors such as socio-economic status were not statistically significant even when the estimate of association was quite large. This is because we could not confirm re-hospitalization status for many participants who might either have moved out from their residential address or could not be contacted for other reasons. Since we were interested only on the factors at baseline or at the time of hospitalization, we did not consider and

Table 3: Adjusted associations with mortality within $\mathbf{3 0}$ days of initial hospitalization for community acquired pneumonia.

\begin{tabular}{|c|c|c|c|c|}
\hline \multirow[t]{2}{*}{ Factors } & \multicolumn{2}{|c|}{ Mortalitya } & \multicolumn{2}{|c|}{ Mortalityb } \\
\hline & OR $(95 \% \mathrm{CI})$ & $\mathbf{P}$ & OR (95\% CI) & $\mathbf{P}$ \\
\hline $\begin{array}{l}\text { Lower socioeconomic } \\
\text { status (Education < } \\
\text { high school) }\end{array}$ & $0.99(0.51,1.92)$ & 983 & $0.98(0.50,1.91)$ & 953 \\
\hline Influenza vaccination & $1.36(0.57,3.21)$ & 488 & $1.21(0.51,2.89)$ & 660 \\
\hline $\begin{array}{l}\text { Pneumococcal } \\
\text { vaccination }\end{array}$ & $0.64(0.32,1.27)$ & 203 & $0.66(0.33,1.32)$ & 243 \\
\hline $\begin{array}{l}\text { Appropriate antibiotic } \\
\text { use }\end{array}$ & $1.71(0.65,4.52)$ & 281 & $1.84(0.69,4.91)$ & 220 \\
\hline Nutrition score & $0.85(0.68,1.06)^{c}$ & 145 & $0.85(0.68,1.06)^{c}$ & 142 \\
\hline $\begin{array}{l}\text { Lower functional } \\
\text { status (Barthel } \\
\text { score } \leq 17 \text { ) }\end{array}$ & $0.72(0.33,1.60)$ & 423 & $0.70(0.31,1.56)$ & 381 \\
\hline Hip Fracture & $4.00(1.46,10.96)$ & 007 & $4.27(1.50,12.18)$ & 007 \\
\hline COPD & $2.31(1.18,4.50)$ & 014 & $2.25(1.15,4.39)$ & 018 \\
\hline $\begin{array}{l}\text { Cerebrovascular } \\
\text { disease }\end{array}$ & $2.11(1.03,4.31)$ & 040 & $2.30(1.11,4.76)$ & 025 \\
\hline
\end{tabular}

aMortality within 30 days vs. alive at 30 days of hospital admission

bMortality within 30 days vs. discharged alive within 30 days of hospital admission (excluding those who remained in the hospitals for more than 30 days)

cOdds ratio for 5 points increment in score 
Table 4: Adjusted association with re-hospitalization within 90 days of initial hospitalization for CAP.

\begin{tabular}{llc}
\hline Factors & OR (95\% Cl) & P \\
\hline $\begin{array}{l}\text { Lower socioeconomic status (Education }< \\
\text { high school) }\end{array}$ & $1.98(0.95,4.13)$ & 069 \\
Influenza vaccination & $0.92(0.39,2.18)$ & 842 \\
Pneumococcal vaccination & $1.45(0.70,3.02)$ & 319 \\
Appropriate antibiotic use & $1.44(0.58,3.57)$ & 428 \\
Nutrition score & $1.17(0.89,1.54)^{\mathrm{a}}$ & 254 \\
Lower functional status (Barthel & $0.70(0.31,1.61)$ & 406 \\
score $\leq 17)$ & & \\
Male Sex & $2.35(1.13,4.85)$ & 022 \\
Vitamin E supplement & $0.37(0.16,0.90)$ & 028 \\
\hline
\end{tabular}

$\mathrm{OR}=$ Odds ratio; $\mathrm{Cl}=$ Confidence interval

aOdds ratio for 5 points increment

adjust any independent predictor of outcomes during hospitalization such as any superinfection e.g., diarrhea; or any other new and serious complications e.g., respiratory failure; or receiving extra medical attention, e.g., ICU admission; or drug related adverse events, e.g., adverse reaction. Some of these conditions might have affected the outcomes [32-34] and are also related to other variables introducing confounding bias as happens in observational studies.

\section{Conclusion}

Chronic comorbidities appear to be the most important predictors of death and re-hospitalization in older adults hospitalized with community-acquired pneumonia. Vitamin E supplementation also appeared to be protective from (re)hospitalization for any disease following discharge from hospitals for pneumonia infection. Other variables that we tested as potentially modifiable to the

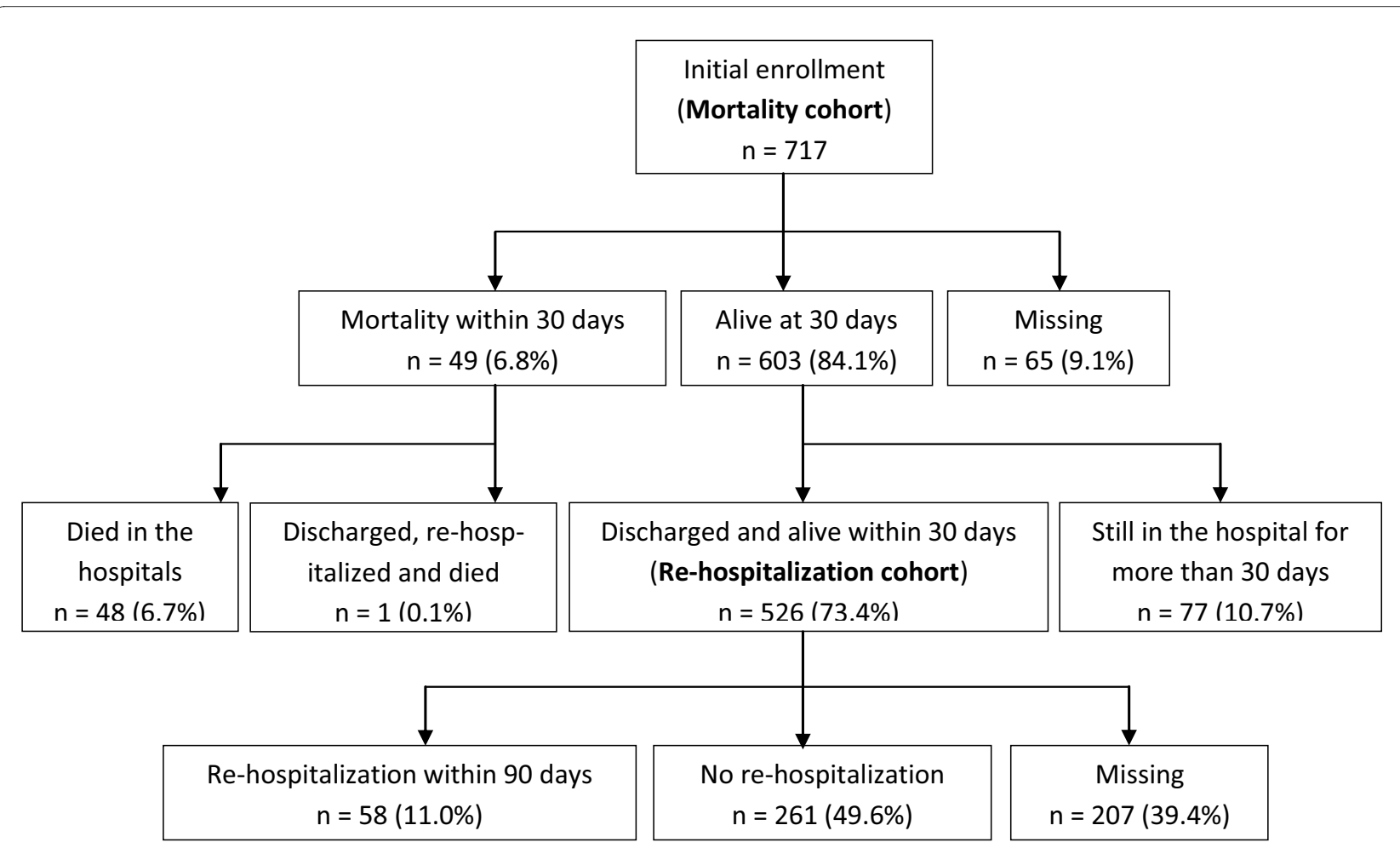

Figure 1 Mortality and re-hospitalization in the cohort of patients hospitalized for community-acquired pneumonia 
in-hospital mortality and rehospitalization did not appear to have any associations.

\section{Competing interests}

The authors declare that they have no competing interests.

\section{Authors' contributions}

BN performed the statistical analysis, interpreted the results and drafted the manuscript. SDW decided analysis approach and helped in interpretation and drafting of the manuscript. PK participated in analyzing the data, interpretation of the results and drafting of the manuscript. TM participated in the design of the study and interpretation of the results. ML conceived of the study, and designed and coordinated the study, decided its analysis approach and helped to interpret the results and to draft the manuscript. All authors read and approved the final manuscript.

\section{Acknowledgements}

Funding was provided from the Canadian Institute of Health Research Interdisciplinary Health Research Team

\section{Author Details}

'Department of Clinical Epidemiology and Biostatistics, McMaster University, Hamilton, Ontario, Canada, 2Department of Family and Community Medicine, University of Toronto, Toronto, Canada, ${ }^{3}$ Dalhousie University, Halifax, Nova Scotia, Canada, ${ }^{4}$ Departments of Pathology and Molecular Medicine, McMaster University, Hamilton, Ontario, Canada and 5 Michael DeGroote Institute for Infectious Diseases, McMaster University, Hamilton, Ontario, Canada

Received: 23 October 2009 Accepted: 11 May 2010

Published: 11 May 2010

\section{References}

1. Fine MJ, Hough $L$, Medsger AR, Li YH, Ricci EM, Singer DE, Marrie TJ, Coley CM, Walsh MB, Karpf M, Lahive KC, Kapoor WN: The hospital admission decision for patients with community-acquired pneumonia. Arch Intern Med 1997, 157:36-44.

2. Bartlett JG, Mundy LM: Community-acquired pneumonia. N Engl J Med 1995, 333:1611-1624.

3. Marrie TJ: Community-acquired pneumonia in the elderly. Clin Infect Dis 2000, 31:1066-1078

4. Loeb M: Pneumonia in older persons. Clin Infect Dis 2003, 37:1335-1339.

5. Fernandez-Sabe N, Carratala J, Roson B, Dorca J, Verdaguer R, Manresa F, Gudiol F: Community-acquired pneumonia in very elderly patients. Causative organisms, clinical characteristics and outcomes. Medicine (Baltimore) 2003, 82:159-169.

6. Kaplan V, Angus DC, Griffin MF, Clermont G, Watson RS, Linde-Zwirble WT: Hospitalized Community-acquired Pneumonia in the Elderly - Ageand Sex-related Patterns of Care and Outcome in the United States. Am J Respir Crit Care Med 2002, 165:766-772.

7. Steel K, Gertman P, Crescenzi C, Anderson J: latrogenic illness on a general medicine service at a university hospital. N Engl J Med 1981, 304:638-642.

8. Herzog NS, Bratzler DW, Houck PM, Jiang H, Nsa W, Shook C, Weingarten SR: Effects of previous influenza vaccination on subsequent readmission and mortality in elderly patients hospitalized with pneumonia. Am J Med 2003, 115:454-461.

9. Vila-Corcoles A, Ochoa-Gondar O, Llor C, Hospital I, Rodriguez T, Gomez A: Protective effect of pneumococcal vaccine against death by pneumonia in elderly subjects. Eur Respir J 2005, 26:1086-1091.

10. Mykietiuk A, Carratala J, Dominguez A, Manzur A, Fernandez-Sabe N, Dorca J, Tubau F, Manresa F, Gudiol F: Effect of prior pneumococcal vaccination on clinical outcome of hospitalized adults with community-acquired pneumococcal pneumonia. Eur J Clin Microbiol Infect Dis 2006, 25:457-462.

11. Garau J, Baquero F, Perez-Trallero E, Perez JL, Martın-Sanchez AM, GarciaRey C, Martın-Herrero JE, Dal-Re R, on behalf of the NACER Group: Factors impacting on length of stay and mortality of community-acquired pneumonia. Clin Microbiol Infect 2008, 14:322-329.

12. Johnson D, Carriere KC, Jin Y, Marrie T: Appropriate antibiotic utilization in seniors prior to hospitalization for community-acquired pneumonia is associated with decreased in-hospital mortality. J Clin Pharm Ther 2004, 29:231-239.

13. Gleason PP, Meehan TP, Fine JM, Galusha DH, Fine MJ: Associations between initial antimicrobial therapy and medical outcomes for hospitalized elderly patients with pneumonia. Arch Intern Med 1999 159:2561-2572.

14. Genne D, Sommer R, Kaiser L, Saaïdia A, Pasche A, Unger PF, Lew D: Analysis of factors that contribute to treatment failure in patients with community-acquired pneumonia. Eur J Clin Microbiol Infect Dis 2006 25:159-166

15. Vecchiarino P, Bohannon RW, Ferullo J, Maljanian R: Short-term outcomes and their predictors for patients hospitalized with community-acquired pneumonia. Heart and Lung 2004, 33:301-307.

16. Riquelme OR, Riquelme OM, Rioseco ZML, Gomez MV, Cardenas G, Torres $\mathrm{C}$ : Community-acquired pneumonia in the elderly: clinical and nutritional aspects. Rev Med Chil 2008, 136:587-593.

17. Cabre M, Serra-Prat M, Force L, Palomera E, Pallares R: Functional status as a risk factor for mortality in very elderly patients with pneumonia. Med Clin (Barc) 2008, 131:167-170.

18. Mody L, Sun R, Bradley SF: Assessment of pneumonia in older adult: effect of functional status. J Am Geriatr Soc 2006, 54:1062-1067.

19. Marrie TJ, Majumdar SR: Management of community-acquired pneumonia in the emergency rooms. Respir Care Clin 2005, 11:15-24

20. Rush D: Nutrition screening in old people: it's place in a coherent practice of preventative health care. Annu Rev Nutr 1997, 17:101-125.

21. Guigoz Y, Vellas B, Garry PJ: Mini nutritional assessment: a practical assessment tool for grading the nutrition state of elderly patients. Facts and Research in Gerontology (supp/ nutrition) 2nd edition. 1994:15-59.

22. Guigoz Y, Vellas B: Assessing the nutritional status of the elderly: mini nutritional assessment as part of the geriatric evaluation. Nutr Rev 1998, 54:s59-s65.

23. Collin C, Wade DT, Davies S, Horne V: The Barthel ADL Index: a reliability study. Int Disability Study 1988, 10:61-63.

24. Lim WS, Eerden MM van der, Laing R, Boersma WG, Karalus N, Town Gl, Lewis SA, Macfarlane JT: Defining community-acquired pneumonia severity on presentation to hospital: an international derivation and validation study. Thorax 2003, 58:377-382

25. Mandell LA, Marrie TJ, Grossman RF, Chow AW, Hyland RH, the Canadian Community-Acquired Pneumonia Working Group: Canadian Guidelines for the Initial Management of Community-Acquired Pneumonia: An Evidence-Based Update by the Canadian Infectious Diseases Society and the Canadian Thoracic Society. Clin Infect Dis 2000, 31:383-421.

26. Restrepo MI, Mortensen EM, Pugh JA, Anzueto A: COPD is associated with increased mortality in patients with community-acquired pneumonia. Eur Respir J 2006, 28:346-351

27. Kothe H, Bauer T, Marre R, Suttorp N, Welte T, Dalhoff K, the Comprehensive Network for Community-Acquired Pneumonia study group: Outcome of community-acquired pneumonia: influence of age, residence status and antimicrobial treatment. Eur Respir J 2008 32:139-146.

28. Muraki S, Yamamoto S, Ishibashi H, Nakamura K: Factors associated with mortality following hip fracture in Japan. J Bone Miner Metab 2006, 24:100-104.

29. Meydani SN, Hayek M, Coleman L: Influence of vitamins E and B6 on immune response. Ann NY Acad Sci 1992, 669:125-39.

30. Loeb M, High K: The effect of malnutrition on risk and outcome of community-acquired pneumonia. Resp Care Clinics of North America 2005, 11:99-108.

31. Palepu A, Sun H, Kuyper L, Schechter MT, Shaughnessy MVO, Anis AH: Predictors of early hospital readmission in HIV-infected patients with pneumonia. J Gen Intern Med 2003, 18:242-247.

32. Jasti H, Mortensen EM, Obrosky DS, Kapoor WN, Fine MJ: Causes and Risk Factors for Rehospitalization of Patients Hospitalized with CommunityAcquired Pneumonia. Clin Infect Dis 2008, 46:550-556.

33. Lodise TP, Kwa A, Cosler L, Gupta R, Smith RP: Comparison of $\beta$-Lactam and Macrolide combination therapy versus Fluoroquinolone monotherapy in hospitalized veterans affairs patients with community-acquired pneumonia. Antimicrol Agents Chemother 2007, 51:3977-3982. 
34. Kornum JB, Tomsen RB, Riss A, Lervang HH, Hchonheyder HC, Sorensen HT: Type 2 diabetes and pneumonia outcomes -- a population-based cohort study. Diabetes Care 2007, 30:2251-2257.

35. Pappas G, Hadden WC, Kozak $\sqcup$, Fischer GF: Potentially avoidable hospitalizations: inequalities in rates between US socioeconomic groups. Am J Public Health 1997, 87:811-816.

\section{Pre-publication history}

The pre-publication history for this paper can be accessed here:

http://www.biomedcentral.com/1471-2318/10/22/prepub

\section{doi: 10.1186/1471-2318-10-22}

Cite this article as: Neupane et al., Predictors of inhospital mortality and rehospitalization in older adults with community-acquired pneumonia: a prospective cohort study BMC Geriatrics 2010, 10:22

Submit your next manuscript to BioMed Central and take full advantage of:

- Convenient online submission

- Thorough peer review

- No space constraints or color figure charges

- Immediate publication on acceptance

- Inclusion in PubMed, CAS, Scopus and Google Scholar

- Research which is freely available for redistribution

Submit your manuscript at www.biomedcentral.com/submit
() BioMed Central 